\title{
Gold Alloys for Precision Resistances
}

\author{
A. S. Darling \\ Johnson Matthey \& Co Limited, London
}

The great stability of gold alloys makes them an ideal basis for the development of precision resistance wires, both for standard resistors in high-accuracy measuring instruments and for potentiometers where a high resistivity is required combined with a low temperature coefficient, low contact resistance and good wearing characteristics.

The ability to measure accurately implies the existence of accurate standards of comparison and this requirement was fully appreciated in the early days of electrical technology. Complete sets of resistance standards produced by Siemens and Halske as early as 1848 (1) contributed greatly towards the success of their cable laying operations, while Matthiessen's work on the electrical properties of metals and alloys was undertaken largely to assist the British Association in their endeavours to produce stable and reliable resistors which embodied and maintained the newly established international standard of the ohm $(2,3,4,5)$.

Some of Matthiessen's experimental findings prompted the following observations by Fleeming Jenkins: "An opinion is very prevalent that the electrical resistances of wires of some, if not all, metals are far from permanent; and since these resistances are well known to vary as the wires are more or less annealed, it is quite conceivable that even ordinary changes of temperature, or the passage of an electrical current, may cause such alterations in the molecular condition of the wire as to alter this resistance" (6). Some evidence to support such extreme arguments was available even in 1860, and Siemens's liquid mercury resistance standard received for this reason a good deal of support, particularly on the Continent.

Solid alloys were, however, easier to handle than liquids and had moreover much lower temperature coefficients of resistance. By correlating the results of resistivity, temperature coefficient and density measurements on many different wires Matthiessen developed very clear ideas on the nature of alloy systems and must have been one of the earliest

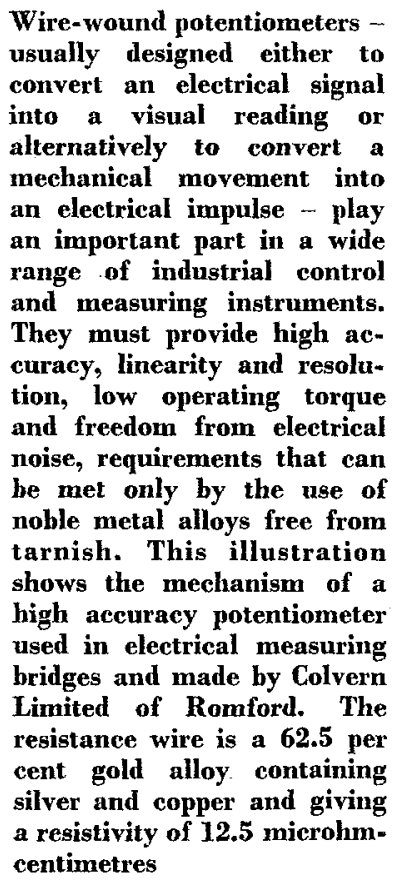

usually designed either to convert an electrical signal into a visual reading or alternatively to convert a mechanical movement into an electrical impulse - play range of industrial control and measuring instruments. They must provide high accuracy, linearity and resolu, low operating torque noise, requirements that can be met only by the use of noble metal alloys free from tarnish. This illustration shows the mechanism of a high accuracy potentiometer Limited of Romford. The cent gold alloy containing silver and copper and giving centimetres

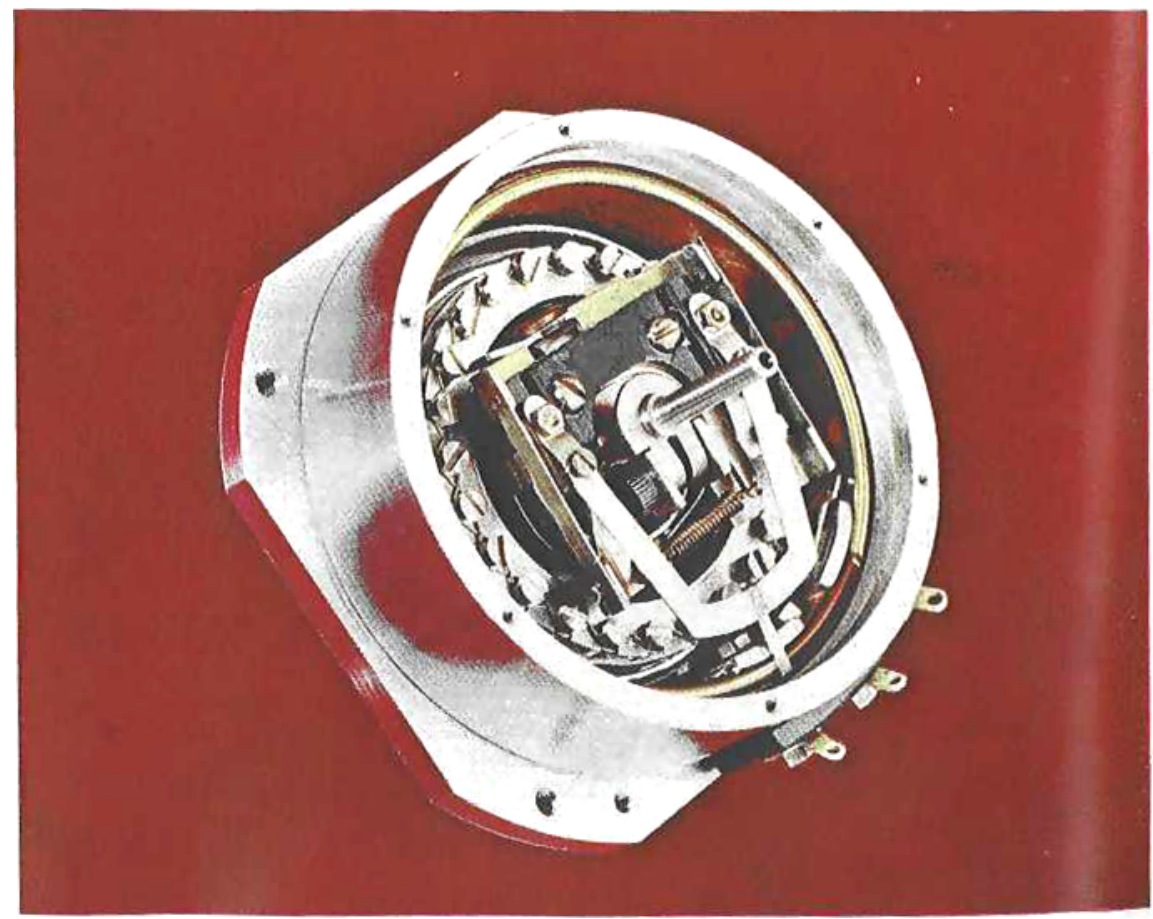


This precision potentiometric transducer, by Delta Controls of Kingston upon Thames, incorporates a Bourdon tube pressure gauge and is used for monitoring changes of pressure in many types of industrial process control equipment. A gold alloy slide wire - 5 per cent molybdenum, 40 per cent palladium and 55 per cent gold was found to give troublefree operation for very much longer periods than experienced with other materials. It has a resistivity of 100 microhm-centimetres with a very low temperature coefficient of resistance

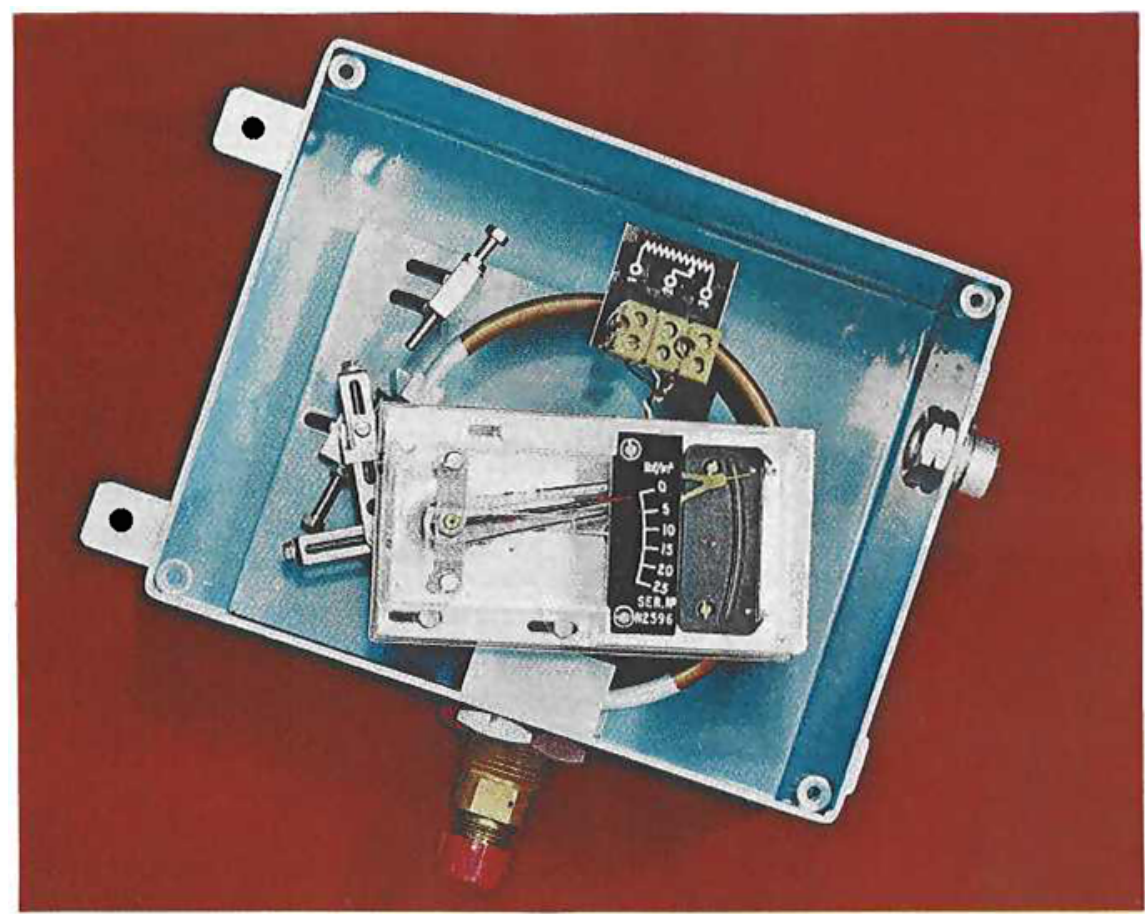

investigators to postulate the existence of metallic solid solutions.

One of the more stable alloys of those he studied contained 66 per cent of gold and 44 per cent of silver. These two metals form a continuous series of solid solutions but they are unfortunately unsuited for most practical applications because of their softness and low resistivity.

Gold forms alloys with palladium, however, in the same way as it does with silver, and the resulting solid solutions form the basis of many widely used resistance alloys. Since the gold-palladium system tends to be regarded as a classical example of one in which the two constituents are soluble in all preparations, its electrical characteristics can therefore be used to illustrate the general principal of resistance alloy development.

Figure 1 illustrates the effect of palladium on the electrical resistivity of gold. The specific resistance of pure gold at $20^{\circ} \mathrm{C}$ is 2.12 microhm $\mathrm{cm}$ and its temperature coefficient of resistance is 0.0040 per deg C. The addition to gold of approximately 63 atomic per cent of palladium increases its specific resistance to 28 microhm $\mathrm{cm}$, and reduces its temperature coefficient to about 0.0005 per deg $C$. The general conclusions to be drawn from this diagram
Fig. 1 The gold-palladium system is generally regarded as a classical example of complete mutual solubility. Although the electrical resistivity and temperature coefficient curves indicate slight deviations from this ideal state, no discontinuous variation of properties with composition occurs and many important resistance alloys are based on this system

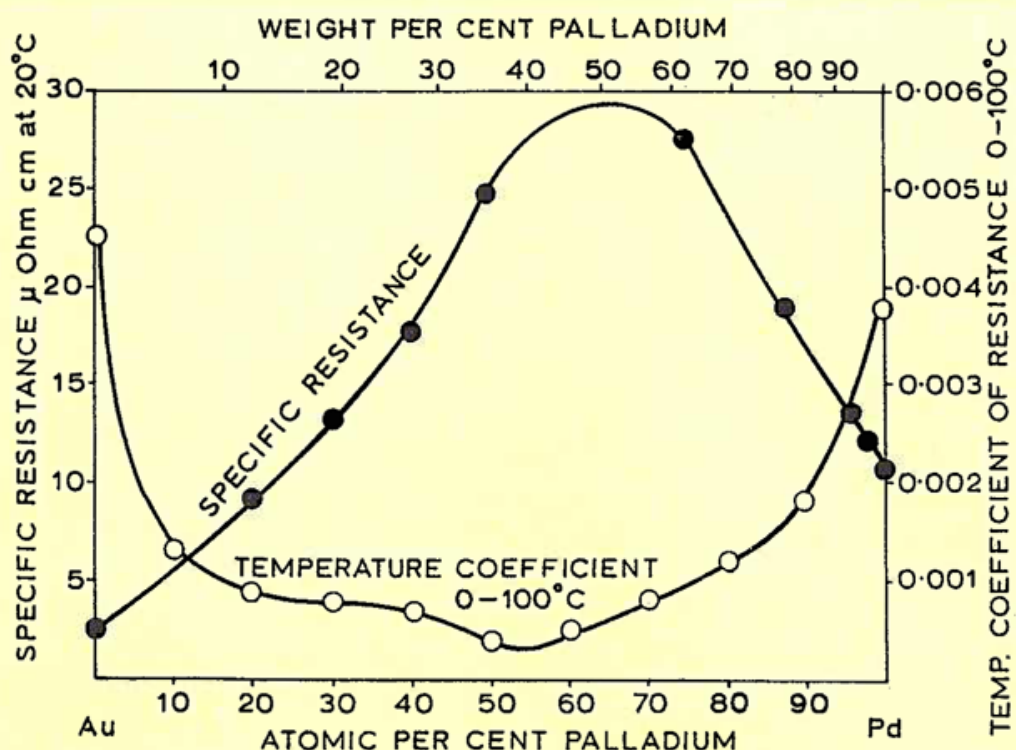


are that high resistivity corresponds with a low temperature coefficient of resistance, and that the resistivity rises to a maximum at what corresponds to the highest degree of alloying. This type of behaviour led Matthiessen to suggest that the total resistance of a metal or alloy could be separated into temperature-dependent and temperature-independent constituents; if we assume the alloying effect to be temperature independent it becomes easy to understand why alloys of high resistivity tend to have low temperature coefficients of resistance.

In the gold-palladium system peak resistivity does not coincide with the lowest temperature coefficient, and the interesting resistivity inflexions which occur between 40 and 50 per cent of palladium suggest that some tendency exists for the alloys to depart from the ideal solid solution state. These deviations, although measurable (7) are fairly minor, however, and the gold-palladium system is widely used as a basis for the development of high-strength gold alloys in which the dual requirements of high resistivity and low temperature coefficient of resistance are obtained without sacrificing the essential requirements of stability and freedom from tarnish and corrosion.

\section{Stability and Resistance to Corrosion}

Very stable materials are needed for the construction of fixed standard resistors, and when alloys for such applications are being selected the requirement for high resistivity is frequently subordinated to other considerations. Resistance constancy is an essential requirement, so that alloys which depend on heat treatment for the development of high resistivity are generally avoided and every attempt is made to employ annealed solid solution wires with an intrinsically low temperature coefficient of resistance. Long-term stability also implies considerable resistance to atmospheric corrosion which affects the surface of wire; if the standard resistor is to be used for precise D.C. measurements it is also important that the wire from which it is constructed should have a low thermal EMF with respect to copper.

While the characteristics of many gold alloys make them very suitable for such critical applications, the over-riding importance of low and constant contact resistance has made the use of noble metal resistance wires almost mandatory for the construction of precision slide wire potentiometers. Gold alloys, because of their freedom from oxide and sulphide film formation find considerable application in such devices, particularly when low contact pressures are involved. When part of the voltage signal generated across the sliding contact manifests itself as electrical noise gold alloys also help to keep this undesirable characteristic within tolerable limits.
In the development of resistance alloys that are to be used as slide wires, base metal additions which are likely to form a stable oxide or sulphide films on the wire surfaces must be avoided as much as possible. Although hard wires are better able to resist the abrasion of a sliding contact, and stronger wires facilitate winding procedures, injudicious attempts to improve by alloying the mechanical properties of soft resistance alloys have, therefore, sometimes resulted in inferior electrical characteristics.

\section{Gold Alloys Containing Iron}

The effect of moderate additions of the more common metals on the room temperature resistivity of gold is illustrated in Fig. 2, based upon the work of Linde. On an atomic basis iron has more effect on resistivity than the other non-reactive elements which are indicated, although binary gold iron alloys have not found a great deal of favour because of their instability and a tendency to form surface oxide films. The alloys can, however, be worked quite easily and gold alloys containing up to 9 per cent by weight of iron and having resistivities within the range 76 to 117 microhm $\mathrm{cm}$ have been described in the literature (8).

Improved results can, however, be obtained by adding iron to gold which already contains palladium (9). The best alloy, containing 10 per cent iron, 40 per cent of palladium and 50 per cent of gold is ductile and very resistant to corrosion, after solution treatment at $800^{\circ} \mathrm{C}$ it has a specific resistance of $75 \mathrm{microhm} \mathrm{cm}$. Subsequent ageing at 400 to $500^{\circ} \mathrm{C}$ increases this value to approximately $180 \mathrm{microhm} \mathrm{cm}$ and positive temperature coefficients as low as 10 parts per million per deg $C$ have been claimed (10). This low temperature heat treatment orders the alloy, and the high resistivity developed is particularly noteworthy as an increase in order is usually associated with a decrease in resistance.

The over-ageing which occurs in this alloy after two hours at $500^{\circ} \mathrm{C}$ reveals itself as a rapid fall in resistivity and it seems probable that the resistivity changes which occur during the earlier stages of heat treatment may be attributable to the transient conditions introduced by partial ordering. The response of this alloy to heat treatment is critically controlled by the composition, Wise (10) having shown that a half per cent fall in the palladium content reduces the final resistivity by approximately 15 per cent. The heat treatment which produces the resistance change also increases the tensile strength of the wire from 50 to 100 tons $/ \mathrm{in}^{2}$. Cold working after ageing obviously destroys the ordered structure to some extent as it reduces the resistivity from 180 to about $80 \mathrm{microhm} \mathrm{cm}$. Although the high resistivities available with this alloy are very valuable, the 

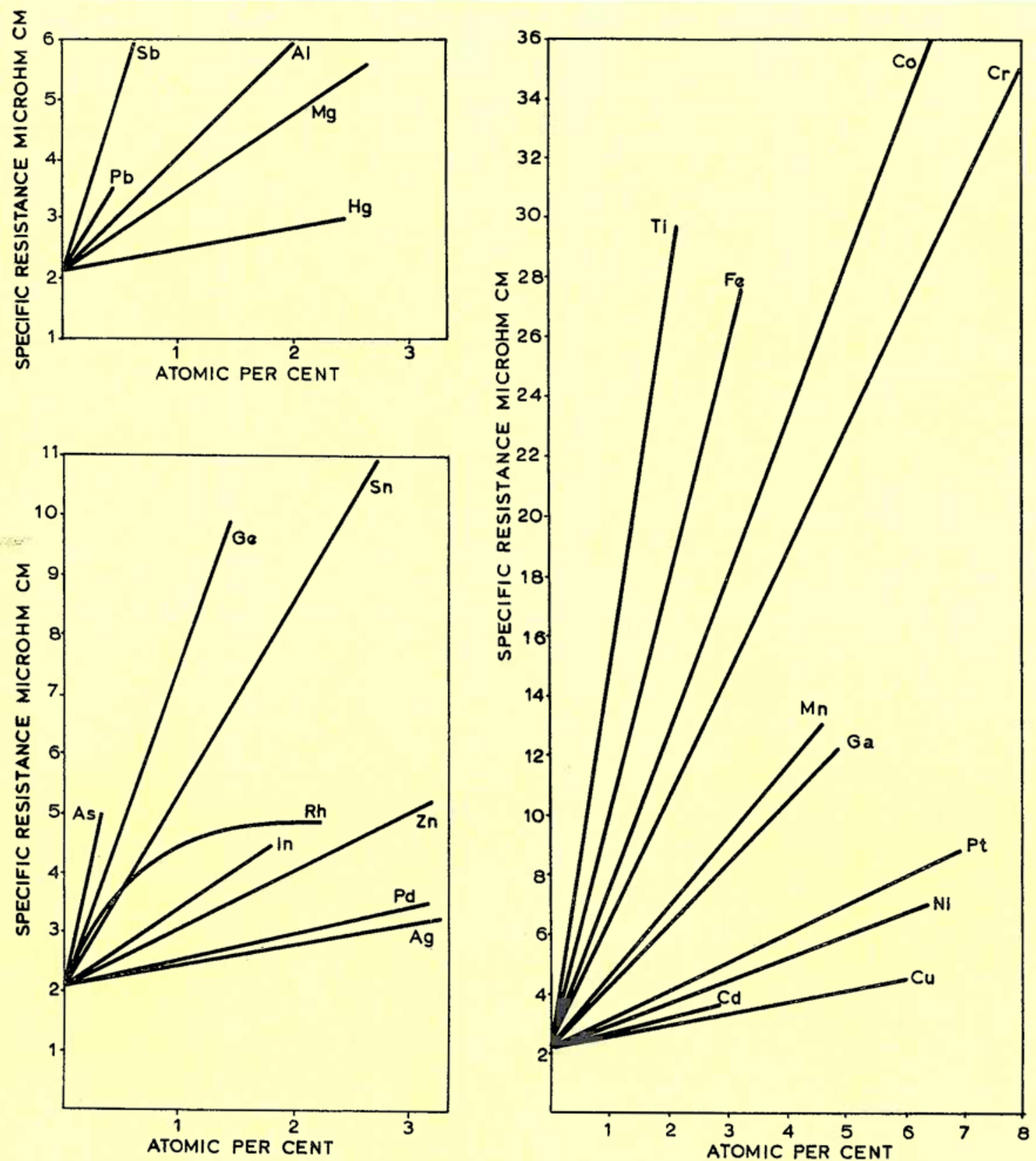

Fig. 2 The effect of the more common alloying additions on the electrical resistivity of gold, after Linde (12). With the exception of reactive elements such as titanium, iron increases the resistivity of gold more rapidly than any other soluble addition

uncertainties associated with the use of wire whose properties are critically dependent upon its composition, and the precise time and temperature of its heat treatment limits it to those applications where high stability and constancy of resistance are not of primary importance.

\section{Gold Alloyed with Chromium and Cobalt}

The possibilities of these alloys were first revealed by J. O. Linde $(11,12)$ who showed that small additions of chromium and cobalt had a considerable influence on the temperature coefficient of resistance of gold. The temperature-resistance curves of both these alloys exhibited a characteristic " $S$ " shaped inflexion near to room temperature, which meant that they could be considered as corrosion resistant alternatives to alloys such as Manganin and Constantan.

The first paper on the use of chromium-gold alloys for the manufacture of standard resistors was published by Thomas of the National Bureau of Standards in 1934 (13). The room temperature 


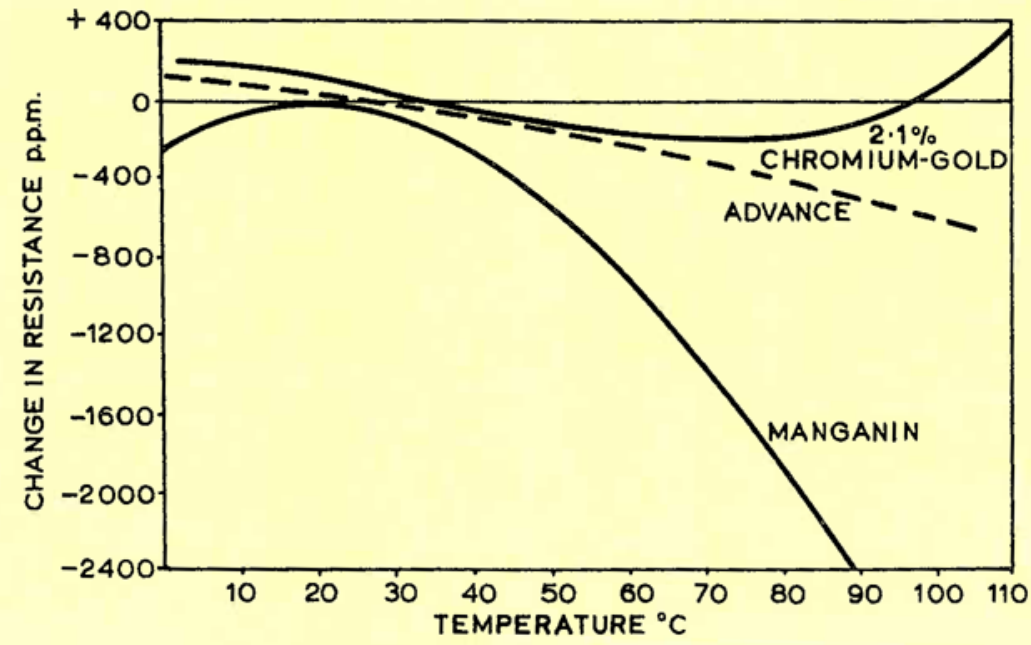

Fig. 3 Curves showing the effect of temperature on the electrical resistance of the 2.1 per cent chromium-gold allow (15). Over the temperature range 0 to $100^{\circ} \mathrm{C}$, the resistance changes encountered are very small indeed compared to those of Manganin and Advance

characteristics of the coil made by Thomas were so good that Godfrey, in a later paper (14) claimed that "the gold-chromium resistance alloys investigated by Linde and Thomas seem to be ideally suited for the production of very precise electrical measuring instruments, such as the bridges used in resistance thermometry. It seems probable that a bridge made with gold-chromium alloy coils without temperature control should be fully as good as the customary bridge with Manganin coils and thermostatic temperature control".

The procedure generally adopted in the manufacture of chromium-gold resistance coils is to employ hard drawn wire containing 2.0 to 2.10 per cent of chromium. This has a positive temperature coefficient and a specific resistance of 33 microhm $\mathrm{cm}$. The wire is wound into coil form and then heat treated at low temperatures until the temperature coefficient has been reduced to acceptably low values. Figure 3, based on the work of H. E. Darling and Newhall (15), indicates that the alloy is usable over the trough rather than the peak of its temperature inflexion, and that resistance changes of less than $130 \mathrm{ppm}$ over the range 20 to $100^{\circ} \mathrm{C}$ are readily attainable. The advantages of this alloy over Manganin and Advance can be well appreciated from this illustration. Very flat resistance curves can be obtained by long ageing treatments at low temperatures, and as shown by Fig. 4, maximum resistance variations of less than $30 \mathrm{ppm}$ over the range 15 to $100^{\circ} \mathrm{C}$ are not unrealistic.

The 2.1 per cent chromium-gold alloy provides very stable fixed resistors, although its low hardness renders it unsuitable for slide wire purposes. It now finds considerable application in the measurement of high pressures by the Bridgeman technique (15).

Here a fine resistance wire is inserted into the pressure vessel and subjected to the hydrostatic pressure of the working fluid. Although the effect of pressure on the electrical resistance of alloy wires is not great it affords one of the few means available for the measurement of very high pressures, determinations up to $6 \times 10^{5}$ atmospheres having been reported. For the majority of pure metals the resistivity initially decreases with increasing pressure because of a

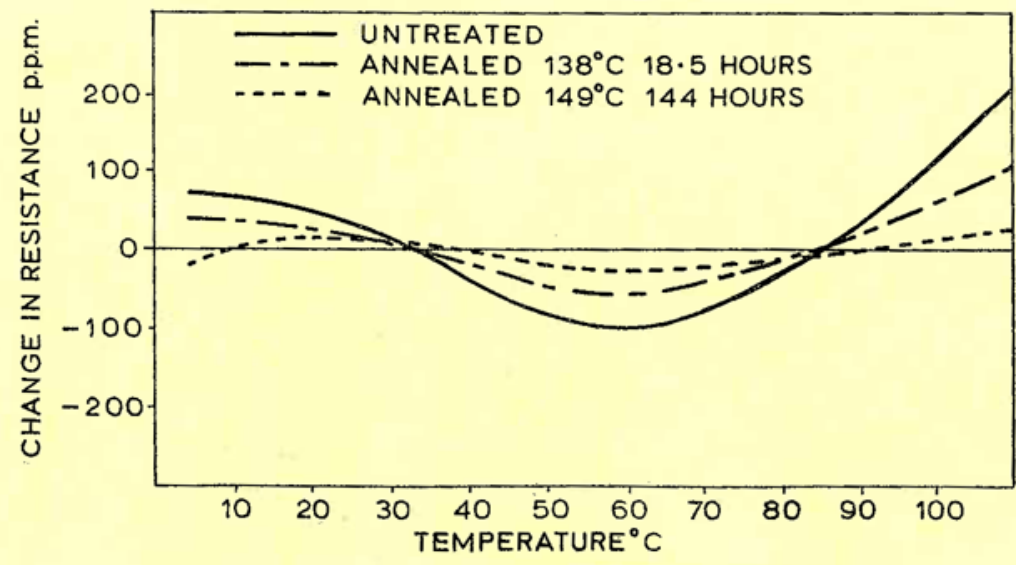

Fig. 4 Effect of low temperature stabilisation heat treatments on the temperature/resistivity variations of chromium-gold wire. By ageing at $149^{\circ} \mathrm{C}$ for 14 hours resistance variations over the range 15 to $100^{\circ} \mathrm{C}$ can be reduced to less than 30 ppm 
reduction in the amplitude of lattice vibrations. Alloying also reduces these lattice vibrations, and we find that dimensional changes, caused by the compressibility of the metal begin to take over from the lattice effect as the degree of alloying increases.

Changes in resistance caused by the pressure change are small compared to those caused by temperature changes, and it is important, therefore, that the wires used for pressure measurements should have a low temperature coefficient of resistance. Although Manganin wires have hitherto been used for this purpose, the measurements are made difficult because of the relatively strong temperature response of this material. Manganin wires need a long time to attain resistance equilibrium after rapid pressure change, whereas chromium-gold responds rapidly and reaches equilibrium within a second or two of the change of pressure. It is also free from the annoying resistance drift which is characteristic of Manganin at high pressure.

The changes in resistance which occur when chromium-gold and Manganin wire are subjected to high pressures are illustrated in Fig. 5. Although the pressure sensitivity of the chromium-gold alloy is only about one-third that of Manganin, pressure

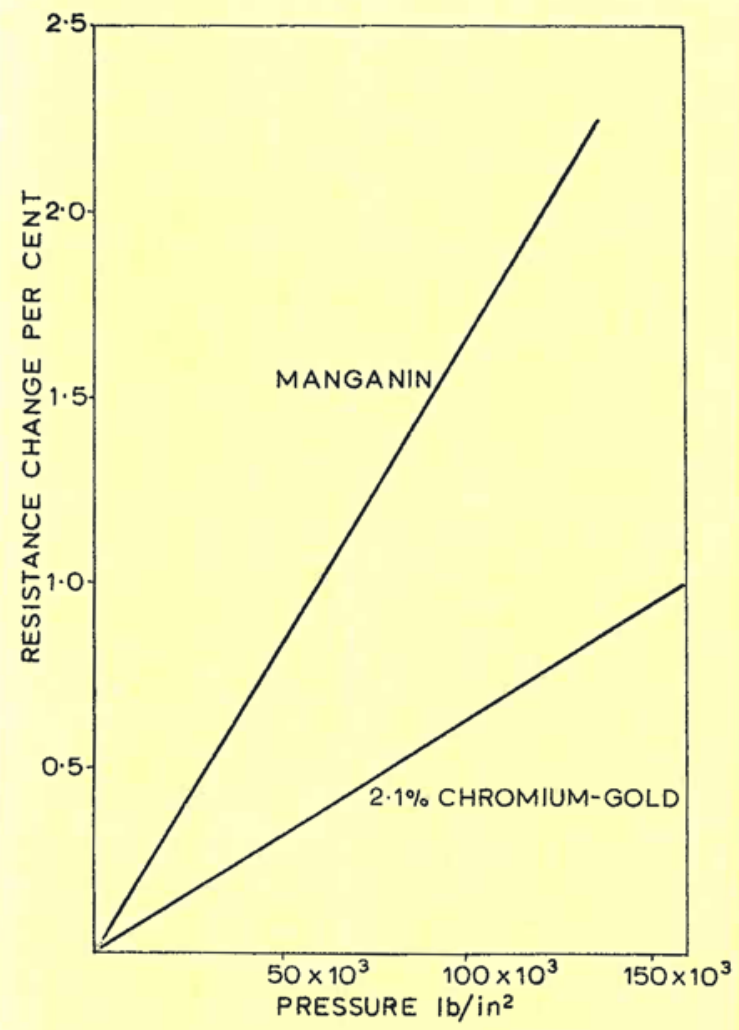

Fig. 5 Effect of pressure on the resistivity of the 2.1 per cent chromium-gold alloy. Hydrostatic pressures of 50 tons $/ \mathrm{in}^{2}$ increase the resistance of this material by about $\frac{1}{2}$ per cent, and the pressure resistance relationship is completely linear

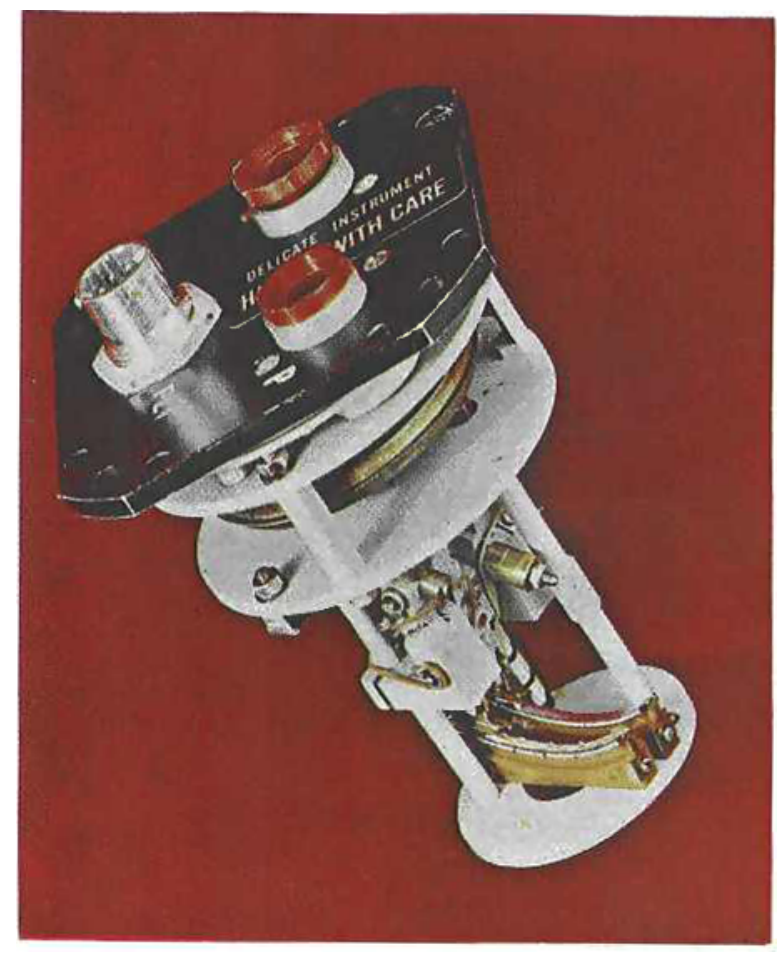

This precision transducer, by Penny and Giles of Christchurch, transmits a continuous reading of air speed to the crash recorder used by most international air lines, the potentiometer converting the movements of a pressuresensitive diaphragm to electrical signals. It is wound with the high resistivity molybdenum-palladium-gold alloy with a copper-silver-gold alloy wiper

variations can be more accurately measured because the low temperature sensitivity reduces measuring ambiguities to negligible proportions. The pressure response of chromium-gold is claimed to be linear within limits of \pm 0.25 per cent.

Although chromium-gold alloys have not been in general employment for periods long enough to justify extravagant stability claims, the information available suggests that resistance stability is of a fairly high order (16) and compares well with that of fully annealed Manganin coils (14). Resistance increments and decrements of the order of 5 to $10 \mathrm{ppm}$ over about four years have been reported (17). The performance of chromium-gold resistors under load has been described by Schulze and Bender (18). Low temperature coefficient chromium-gold resistors can also be vacuum deposited as thin films on to an insulating substrate (19). The resistor is then protected with chromium and connections are formed with gold leads.

Cobalt-gold alloys were investigated soon after chromium-gold, although they have never been popular because of their high thermal EMF against copper of approximately 47 microvolts per deg C (20). As with the chromium alloys approximately 2.2 per cent by weight of cobalt is sufficient to reduce to zero the mean temperature coefficient of gold at room 


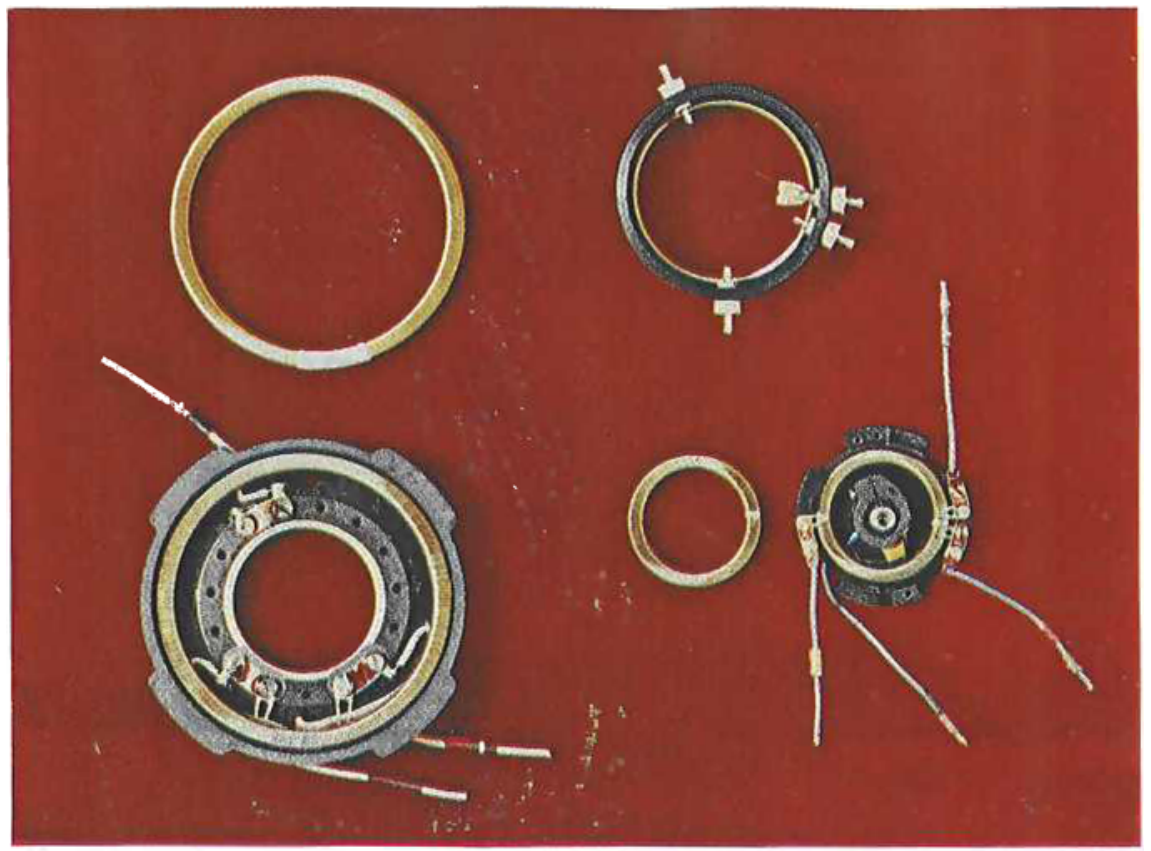

Typical sub-assemblies from the Ferranti range of precision potentiometers, wound with a 75 per cent gold alloy containing also platinum, silver and copper. This alloy, with a resistivity of $80 \mu \mathrm{ohm}$ $\mathrm{cm}$, is very hard wearing with very low contact noise and is used where long life is required, particularly in conditions of vibration such as in aircraft instruments and in industrial weighing systems

temperature, and as can be seen from Fig. 2, cobalt on an atomic basis increases the resistivity of gold rather more than chromium. The alloy with 2.2 per cent by weight of cobait has a specific resistance of $30 \mathrm{microhm} \mathrm{cm}$, is ductile and readily drawn to wire. A temperature coefficient which is virtually zero at room temperature is easily obtained by ageing hard drawn wire at about $140^{\circ} \mathrm{C}$ for 18 to 20 hours.

\section{Gold with Palladium and Molybdenum}

From the brief review so far provided it will be apparent that except for the gold-palladium alloy which contained iron and developed a high resistivity by heat treatment, no gold based alloys of very high resistivity and low temperature coefficient of resistance were available before the early 1960s. The demand for stable and abrasion resistant wires from which high resistance potentiometers could be wound, led, therefore, to a systematic investigation of many gold based alloy systems.

Although many base metal additions had a considerable effect on the resistivity of gold, limitations existed on the quantities which could be safely added without the formation of troublesome surface oxide skins. The best results were obtained by adding smaller quantities of base metals to a binary solid solution of gold with palladium. Molybdenum was the most effective base metal addition and the composition finally selected for general purposes contained 50 per cent by weight of gold and 5 per cent of molybdenum, the balance being palladium (21). This composition was selected as showing a good balance between resistivity and workability. It has a specific resistance of exactly 100 microhm $\mathrm{cm}$ which

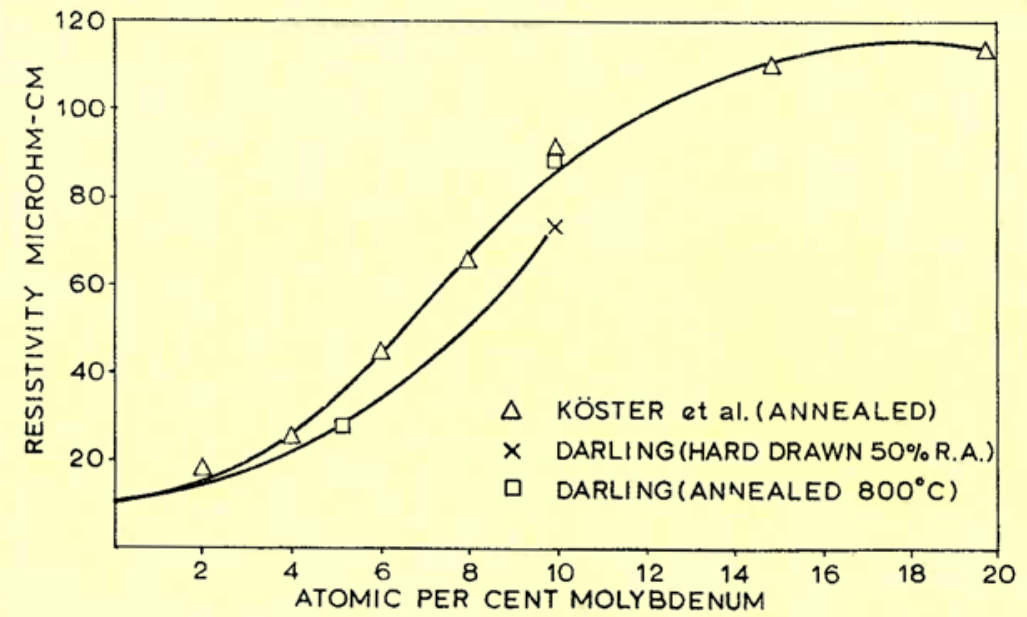

Fig. 6 Cold working decreases the electrical resistivity of molybdenum-palladium alloys, but this effect is greatly modified by the addition of gold. The resistivity of 100 microhm$\mathrm{cm}$ of the gold alloy is not changed appreciably by working or heat treatment 
does not change appreciably either by working or heat treatment. Its temperature coefficient of 0.00012 per deg. $\mathrm{C}$ between $0^{\circ}$ and $100^{\circ} \mathrm{C}$ is acceptably low for most purposes and its high tensile strength, which approaches 70 tons $/ \mathrm{in}^{2}$ in the hard drawn condition, ensures adequate resistance to abrasion and facilitates winding. Its thermal EMF with respect to copper at room temperature is $1.8 \mathrm{~V}$ per deg $\mathrm{C}$.

The resistance stability of this alloy is particularly noteworthy as it is normal to expect heavy plastic deformation to increase the electrical resistance of a metal or alloy by 1 or 2 per cent. Interesting and obscure effects are, however, exhibited by certain transition element alloys, and as shown in Fig. 6, taken from earlier work by the present writer (22), hard drawn molybdenum-palladium alloys have an electrical resistance which is considerably below that of fully annealed material. The high gold content of the ternary alloy described above has evidently modified this effect without destroying it completely. Resistance constancy is probably obtained because the normal increases due to cold working tend to neutralise the decrease attributable in the binary alloy to the destruction of short range order. Some interesting studies of the effect of cold working on the resistivity of gold based alloys have recently been described by Linde (23).

\section{Contact Resistance}

Many of the gold alloy wires previously described are intended for use in precision slide wire potentiometers where contact loads do not exceed a few grammes. The effect of load on the contact resistance of the gold-palladium-molybdenum alloy is shown in Fig. 7. The wiper used for these determinations contained 62.5 per cent by weight of gold, the remainder being silver and copper. Resistance measurements were made by the potential drop method, at currents of 10 milliamps. The contact resistance of the gold-molybdenum alloy increases from about 55 milliohms at 14 grammes to 100 milliohms at 3 grammes. At lower pressures the resistance increases rapidly with decreasing load.

The relationship between load and contact resistance is well defined with noble metal slidewires. Similar relationships are not observed with base metal slidewires such as cupro-nickel and nickelchromium resistors. Although low contact resistances are occasionally obtained with such materials, load and contact resistance are not uniquely related and very scattered results are observed. This scatter is one manifestation of the high noise values generated between sliding contacts and base metal resistance wires which are therefore unsuited for low load, low torque potentiometers.

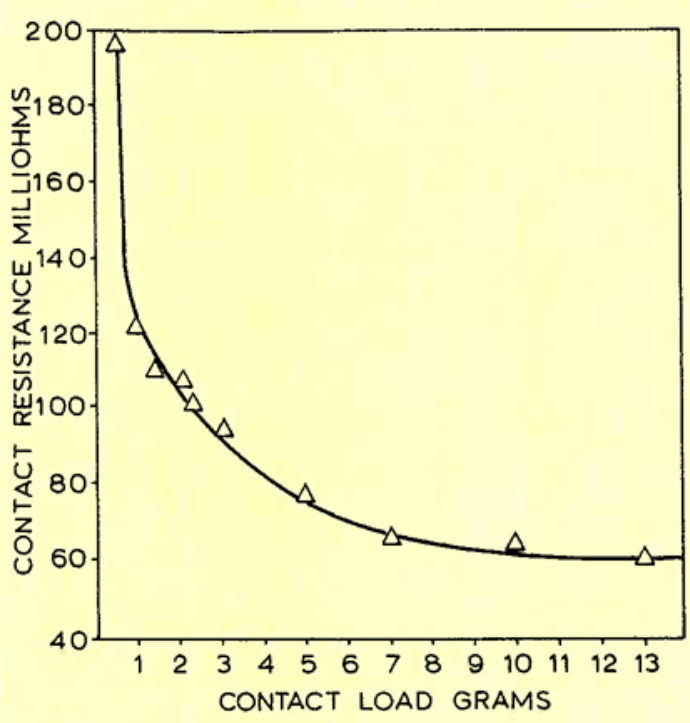

Fig. 7 Effect of load on the contact resistance between a gold-palladium-molybdenum slidewire and a 62.5 per cent gold alloy wiper. Fairly constant contuct resistances are achieved at loads of more than 10 grammes

\section{References}

1 W. Siemens, Pogg. Ann., 1950, 79, 481

2 A. Matthiessen, Trans. Roy. Soc., 1860, 150, 161

3 A. Matthiessen, Phil. Mag., Feb. 1857

4 A. Matthiessen and C. Vogt, Trans. Roy. Soc., 1864, 154,167

5 A. Matthiessen and M. Von Bose, Trans. Roy. Soc., $1862,152,1-27$

6 British Association Reports on Electrical Standards. First report, 1862 (reprinted in 1913 by Cambridge University Press)

7 W. Köster and T. Halpern, Z. Metallk., 1961, 52, (12), 821

8 E. Scheil, H. Specht and E. Wachtel, Z. Metallk., 1958, 49, 593

9 Baker, U.S. Patent 2,780,543, 1957

10 E. M. Wise, Gold Recovery Properties and Applications, D. Van Nostrand, Princeton, 1964, p. 301

11 J. O. Linde, Ann. Physik, 1932, 15, (5), 219

$12 \mathrm{~J}$. O. Linde. Elektrische Widerstandseigenschaften der verdunnten legierungen des Kupfers, Silbers und Goldes. Gleerupska Univ. - Bokhandeln, Lund, Sweden, 1939

13 J. L. Thomas, U.S. Bureau of Standards, $\mathscr{F}$. Research, $1934,13,681$, R.P. 737

14 T. B. Godfrey, U.S. Bureau of Standards, F. Research, 1939, 22, 565, R.P. 1206

15 H. E. Darling and D. H. Newhall, Trans. Amer. Soc. Mech. Eng., 1953, 75, (3), 311

16 A. Schulze, Z. Angew. Phys, 1952, 4, (9), 321

17 A. Schulze, Phys. Zeit., 1940, 41, (6), 121-128

18 A. Schulze and D. Bender, Z. Angew. Physik, 1954, 6, (3), 132

19 U.S. Patent 3,356,982

20 J. L. Thomas, Bureau of Standards, F. Research, 1935, 14, 589, R.P. 789

21 Johnson Matthey, British Patent 861,646

22 A. S. Darling, Platinum Metals Rev., 1968, 12, 54

23 J. O. Linde, Helv. Phys. Acta., 1968, 41, (6-7), 1007 